\title{
Die Liebe zu Gott im Alten Testament.
}

\section{Von Georg Winter.}

Es darf von vorn herein bezweifelt werden, ob man im Alten Testament von einer Liebe zu Gott in unserem Sinne des Wortes reden kann, insofern nämlich dieser Ausdruck für das christliche Gefühl seinen Gegensatz findet in der selbstsüchtigen Liebe zur Welt, dem

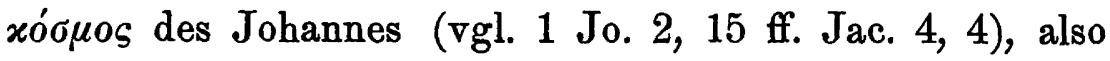
eine überwiegend sittliche Bedeutung hat. Jedenfalls ist die Möglichkeit nicht ausgeschlossen, im A. T. als Gegensatz der Liebe zu dem Gott Jahwe vielmehr die Liebe zu anderen Göttern anzutreffen; dann würde hier die Liebe zu Jahwe einen wesentlich religiösen Inhalt haben $\mathrm{d}$. h. sich nur auf das Verhalten Israels seinem Gott gegenüber beziehen. Eine Untersuchung dieser auftauchenden Frage, die $\mathrm{m}$. W. noch nicht eingehender behandelt worden ist, dürfte namentlich zur Beurteilung des in den biblischen Theologien A. und N. T. oft besprochenen Gebotes Dt. 6, 5 von etlichem Belang sein. Derselben näher nachzugehen, zugleich aber einige Anhaltspunkte über das Alter der Vorstellung einer Liebe zu Jahwe im A. T. zu gewinnen, soll die Aufgabe des folgenden kleinen Aufsatzes sein.

Die Liebe zu Jahwe erscheint im A. T. am häufigsten im Deuteronomium und in deuteronomistischen Stücken, nämlich ' אהב : Dt. 5, 10. 6, 5. 7, 9. 10, 12. 11, 1 . 13. 22. 13, 4. 19, 9. 30, 6. 16. 20. Jos. 22, 5. $23,11$. 1 Kön. 3, 3;

sonst verhältnismäfsig selten : Ex. 20, 6 (vgl. Dt. 5, 10. Neh. 1, 5. Dan. 9, 4). Ri. 5, 31. Jes. 41, 8. Jer. $2,2$. Ps. 31, 24. 97, 10. 145, 20. 2 Chron. 20, 7;

' אהב את-שם : Jes. 56, 6. Ps. 5, 12. 69, 37. 119, 132 ; : Ps. 18, 2.

קפ : Ps. 73, 25; 
dazu noch an 2 Stellen der Ausdruck ,fremde Götter lieben" (ארב) : Jer. 2, 25. 8, 2.

Endlich bringen die Lexica unter $70 \pi$ eine Anzahl Stellen bei, an denen dies Wort im Sinne von Liebe zu Gott stehen soll; jedoch, wie mir scheinen will, mit sehr anfechtbarem Rechte. Das A. T. gebraucht ' $n$ zunächst vom Verhältnis Gottes zu den Menschen = Gnade; als ein Abbild dieses Verhaltens Gottes (vgl. 1 Sam. 20, 14.

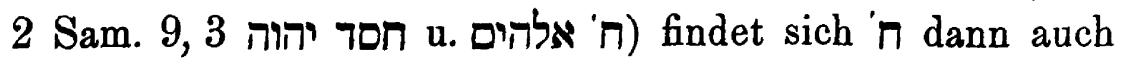
vom Verhältnis der Menschen zu Menschen und zwar der Höherstehenden zu Niederen, der Starken zu Schwachen, der Mächtigen zu Hülfsbedürftigen im Sinne von Güte, Barmherzigkeit, Wohlthun. Ziemlich selten wird das Wort bei Gleichstehenden gebraucht; nie aber (nicht blos sehr selten, wie man überall lesen kann) wird es angewandt von Niederen. Höheren gegenüber ${ }^{1}$ ). Von ' 7 Gott gegenüber zu reden, würde also für das Gefühl des Hebräers dasselbe bedeutet haben wie für das unsere etwa der Ausdruck : gütig sein gegen Gott. Schon dies mufs zur äufsersten Vorsicht mahnen und nur zwingende Notwendigkeit könnte die Bedeutung Liebe zu Gott für ' $n$ empfehlen. Hupfeld, der zu Ps. 4, $4^{2}$ ) letztere zwar noch annimmt, erklärt sie aus dem angegebenen Grunde für „mifsbräuchlich“. Als die loci classici für dieselbe gelten Hos. 6, 4. 6. Jer. 2, 2; aber auch in Bezug auf Hos. 4, 1. 10, 12. 12, 7. Mich. 6, 8. Jes. 57, 1 schwanken die Ausleger.

Zunächst Hos. 10, 12 f. : „Säet euch nach der Gerechtigkeit, erntet nach dem Gebot der Güte (de Wette

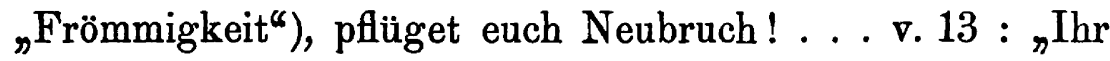
habt Frevel gepflügt, Ruchlosigkeit geerntet, Frucht der

1) Ueber Ruth 3, 10, was man vielleicht dagegen anführen könnte, s. unten S. $249 \mathrm{f}$.

2) In der 1. und 2. (von Riehm besorgten) Ausgabe der Psalmen; Nowack hat in der 3. Ausgabe die hierher gebörenden Ausführungen gestrichen. 
Lüge gegessen ...* Das 2. Glied von v. 12 ist hier ebenso Aufforderung wie das 1. und 3.; man kann es nicht als Verheifsung betrachten (wie Ewald und Nowack in den Commentaren z. St.) und dann auffassen (Ewald u. Wünsche z. St.). Dagegen vgl. Simson z. St., dessen Gründen man noch beifügen kann, dafs auch sonst bei Hosea (12, 7, vgl. Mich. 6, 8) zum Ueben von Recht und Güte nebeneinander aufgefordert wird. Allerdings ist das Ernten nach der Güte hier als Frucht des Säens nach der Gerechtigkeit hingestellt, aber Säen und Ernten ist gedacht als Anfang und Vollendung des sittlichen Handelns : wenn Israel sein ganzes Thun und Treiben wieder mit Gerechtigkeit beginnt, dann wird es dasselbe auch in Liebe weiterführen und vollenden. Also : beginnt all euer Thun mit Gerechtigkeit, vollendet es in Güte, ja fangt ganz von neuem an, ändert eure Gesinnung ganz und gar. Die 3 Imperative v. 12 enthalten so deutlich eine Steigerung; dem Handeln nach der Norm des Rechten (צרקה) tritt das Thun gemäfs der Güte und Nächstenliebe (7Dח) ergänzend und überbietend zur Seite, und beides wird schliefslich gesteigert zur gänzlichen Umwandlung des Sinnes ${ }^{1}$ ). Das Gegenteil von צדקה und

1) Obige Erklärung der Stelle ist im wesentlichen die von Simson; ähnlich auch Keil. Sie wird erfordert durch den v. 12 a adversativ parallelen v. 13 a. v. 13 a kann man keinesfalls verstehen : ibr habt Frevel gepflügt und dafür als Vergeltung Unbilde, Unglück von aufsen her, geerntet, wie z. B. Hitzig, Wünsche, Nowack. Wie matt wäre daun das gewaltige : ז. 14, an dessen Stelle man einen Hinweis erwarten müfste, dafs sich das vorhandene Unglück nun noch vermehren werde. v. 13 blickt der Prophet nicht auf vergangenes Unglück ( der Tiefe der Verworfenheit des Volks, in die es seiner Kriegsmacht vertrauend gesunken ist : Das Unrecht, welches ihr gesäet, der Frevel, mit dem ibr begonnen, ist nun aufgegangen; als Frucht habt ihr geerntet vollständige Verkehrtheit, vollständige Ruchlosigkeit (עלול); so tief seid ihr darein verstrickt, dafs ihr geradezu von Trug und Lüge lebt. Und nun. bringt v. 14 die Vergeltung : ${ }_{n}$ (darum) wird sich Ge- 


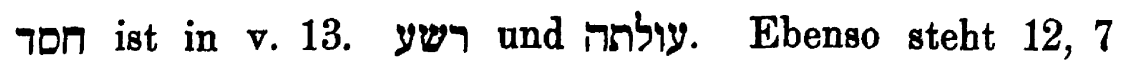
חס (de Wette wiederum „Frömmigkeit") ergänzend neben משפט; zu diesen beiden sittlichen Pflichten tritt dann die sie bedingende religiöse : beständiges Vertrauen auf Gott. Dieser Zusammenstellung entspricht ferner genau Mich. 6, 8, wo gefordert wird : das Thun von משפט, Lust zur Tסח und demütiges Wandeln mit Gott ${ }^{1}$ ). Jes. 57, 1 finden

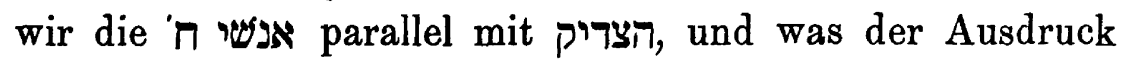
' $\boldsymbol{n}$ ' ' $\Pi$ ' $\kappa$, als der seinem Mitmenschen gegenüber Gütige und Barmherzige, dem אבורי, dem Harten und Unbarmberzigen gegenübersteht (vgl. Mich. 7, 2 ישר gegenüber den blutgierigen Unmenschen). Hos. 4, 1 ist אמת : Treue und Güte in Worten und Werken, eine Verbindung, die man auch sonst häufig im A. T. als Zusammenfassung der sittlichen Pflichten antrifft (vgl. z. B. Prov. 3, 3. 16, 6. 20, 28). Keine Treue ist im Lande, weil keine Güte und Liebe, und beides ist nicht vorhanden, weil das bedingende religiöse Motiv fehlt, die דעת אלהים, die innere Aneignung des Willens Gottes. Hosea scheint hier geradezu mit $1 \pi$ und ' $\$$ den Inhalt der Thora zusammenfassen zu wollen. Denn die sittlichen Schäden, die er ihnen gegenüber v. 2 aufzählt, bringt er wohl in Anlehnung an den Dekalog, der damals innerhalb der prophetischen und priesterlichen Lehre vielleicht schon eine hohe Bedeutung hatte, und die רעת אלהים, die v. 1 die

tümmel erheben wider dein Volk!" So enthalten die 3 Glieder v. 13 a entsprechend v. 12 a ebenfalls eine Steigerung, nur eine Steigerung der Verderbtheit des Volkes. Zu den Gedanken vgl. 5, 4a. 7, 2 b.

1) Welchen Inhalt die in den obigen Stellen enthaltenen Forderungen für den Israeliten hatten, zeigt in lehrreicher Weise Sach. 7, 9 f., der dieselben in etwas breiterer Ausführung wiederholt.

2) Hier erklärt noch Simson ' $\Pi$ als Liebe zu Gott (vgl. Simson zu Hos. 6, 6), obwohl der Sinn des Wortes durch die v. 2 folgenden Gegensätze vollkommen klar ist. 
bedingende religiöse Grundlage von ' $\pi$ und ' bildet, steht v. 6 parallel mit der תורת אלהים (vgl. Nowack zu 8, 12 S. 153).

Es kann kein Zweifel sein, dafs an all den besprochenen Stellen ' $\pi$ ein rein sittlicher Begriff ist und nur bedeutet : liebevolles, gütiges Verhalten dem Nächsten gegenüber, welches allerdings religiös motiviert wird, insofern die ' רעת יח darüber belehrt, dafs Gottes Wesen selbst ist (vgl. Jon. 2, 9. Ps. 144, 2) und dafs sein Wille von den Menschen das Ausüben von ' $\pi$ fordert. Dagegen sind bezüglich Hos. 6, 4. 6 fast alle neueren Ausleger darin einig, das Wort in der Bedeutung "Liebe zu Gott" zu nehmen. Nur Keil macht eine Ausnahme und versteht es auch hier als „Wohlwollen gegen die Mitmenschen, das aus der Liebe zu Gott fliefst"; und Hitzig will wenigstens in v. 6 die Bedeutung „Nächstenliebe ${ }^{*}$ zulassen, was auch Nowack nicht ganz verwirft. Doch ist nicht daran zu denken, dafs man dem Wort v. 6 eine andere Bedeutung beilegen könnte als v. 4. Es hat diese fast durchgehends unrichtige Auffassung der ' $m$ an dieser Stelle ihren Grund in der schwierigen Frage nach der Gedankenverbindung zwischen 6,1-3 und v. $4 \mathrm{ff}$.

Simson und ähnlich Wünsche erklären den Uebergang von $\nabla .3$ zu v. 4 folgendermafsen : ${ }_{n}$ So lange sie nicht also [wie 6, 1-3] denken und sprechen, so lange ihre Liebe so unstät und vergänglich bleibt, wie jetzt, könne der Ewige ihr Heil nicht schaffen" u. s. w. Simson fafst also 6,1-3 im Anschlufs an 5, 15 als Beispiel, wie einst das sich wahrhaft bekehrende Volk reden solle. Doch wird ein solcher Zwischengedanke zwischen 6,3 und v. 4 durch nichts angedeutet. $v$. $4 \mathrm{ff}$. können nur die Antwort Jahwe's auf die Worte des sich an ihn wendenden Volkes sein (Hitzig). Dann darf man aber v. 1-3 nicht in eine ferne Zukunft verlegen, wo Israel einmal so sprechen werde, sondern die Verse sind Ausdruck der Stimmung des durch 
die furchtbaren Drohungen c. 5 und die teilweise schon eingetroffenen Strafen Jahwe's erschütterten Volkes. Warum aber weist Gott $\nabla$. 4 ff. das sich bekehrende Volk zurück? Ewald u. a. fassen die vv. 1-3 als Ausdruck „balber, in der Verlegenheit gegebener Versprechen", einer nur "scheinbaren Reue"; v. 3 findet Ewald „fast spöttelnd". Doch bietet der Wortlaut an sich zu einer derartigen Auffassung keine Veranlassung (vgl. Simson z. St. gegen Ewald). Vielmehr scheinen die Verse den ernstlichsten Eifer des Volks zur Umkehr auszudrücken; man beachte namentlich จ. 3 : „lafst uns erkennen, eifrig trachten (נרדפה), Jahwe zu erkennen" (Wünsche, Hitzig). Man darf sich zum Verständnis an 5, 4-6 erinnern, da c. 5-7 ein Ganzes (Simson, Wünsche, Nowack) bilden. „Ihre Handlungen erlauben ihnen nicht umzukehren zu ibrem Gott; denn ein Geist der Hurerei ist in ihnen, und Jahwe erkennen sie nicht $^{\text {“ }}$ v. 4. So tief also sind sie in ihre Laster verstrickt, so verwirrt ist ihr sittliches Urteil, dafs sie gar nicht mehr zurück können, dafs es ihnen gar nicht mehr möglich ist, Jahwe wahrhaft zu erkennen, wenn sie es auch wollten. Darum werden sie, wenn das Verderben über sie kommt v. 5, in ihrer Unkenntnils Gottes Jahwe mit Schafen und Rindern suchen, aber ihn freilich auf diesem Wege nicht finden v. 6. Was der Prophet 5, 6 voraussagt, das sieht er 6,1-3 schon eingetroffen. Die Worte sind zunächst Folge der Drohung 5, 15, aber gewils nicht gedacht als Erfüllung der in dem letzteren Vers gestellten Bedingung, nicht als ein Ausdruck wahrer Bulse. Das zeigt die Abweisung von Seiten Gottes 6, 4. Der Zusammenhang von 5,15 und $6,1 \mathrm{ff}$. ist vielmehr der, dafs nun das von der furchtbaren Drohung aufs äufserste betroffene Volk die 5, 15 gestellte Bedingung, Bufse zu thun und Gottes Angesicht zu suchen, möglichst schnell zu erfüllen sucht. Soweit ist Ewald zuzustimmen. Aber in dem Munde des Volkes sind die Worte : לפו ונשובה אל-יהוה V. 1 und 
ונרעה נרדפה לרעת את-י' gewifs recht ernstlich gemeint ${ }^{1}$ ). Sie sind jedoch als Rede des wohl geängsteten, aber sittlich nicht gebesserten Volkes cum grano salis zu verstehen : was dieses tief verderbte Geschlecht eben mit Erkenntnis בקש את-י' Jahves meint, nämlich nichts anderes als das 5, 6. Eine wahre Erkenntnis Gottes und wahrhafte Umkehr zu ihm gestatten ja ihre Handlungen nicht 5, 4. Und mit einem Hinweis auf diese sittliche Beschaffenheit mufs darum auch Gott 6, 4 ff. das Volk abweisen und neue Gerichte androhen. Was nützt ihm solches äufserliches Suchen, da das erste Zeichen wahrer Gotteserkenntnis, Güte und Wohlthun, wenn überhaupt einmal vorhanden, flüchtig ist wie Morgengewölk und Morgentau! (v. 4). Gott will ja, dafs ihn sein Volk mit Thaten der Güte suche, wie sie aus der wahren Erkenntnis seiner selbst entspriefsen, nicht mit Opfern v. $6^{2}$ ). Dieser Vers, welcher den in v. 4 der Rede des Volks gegenüber zunächst nur angedeuteten Gedanken noch einmal deutlich ausspricht, belegt zugleich die Richtigkeit unserer Behauptung, dafs v. 1-3 in Hinblick auf 5,6 und als Erfüllung des hier Vorausgesagten aufzufassen sei. Die Worte, dafs Gott an den Opfern keinen Gefallen habe, hätten sonst in dem übrigen Gedankengang der Stelle, der zwar auf die sittliche Verworfenheit des Volkes näher eingeht, aber von seinem verkehrten Eifer, in äufserlichem

1) Ganz entsprechend ist 8, 2 : "mein Gott, wir Israel erkennen Dich" und die Antwort Gottes v. 3.

2) Genau derselbe Gedanke wie Am. 5, 21-24. Mich. 6, 6-8. Schon diese ganz parallelen Stellen beweisen die Richtigkeit der obigen Auffassung dieses Verses zur Genüge. Wie Jeremia unsere Stelle verstanden hat, zeigt Jer. 9, 23, ein Vers, der Hos. 6, 6 nachzuahmen scheint : wer sich rühmen will, der rübme sich einsichtig zu sein und mich zu kennen, dafs ich Jahwe Gnado (7DП), Recht und Gerechtigkeit übe im Lande, denn an diesen habe ich Gefallen, spricht Jahwe. Also was die Gotteserkenntnis bewirken soll, ist : Güte, Recht und Gerechtigkeit. 
Dienst Jahwe zu suchen, nichts sagt, gar keinen Anhalt, sondern ständen als allgemeine Sentenz zusammenhangslos da. V. $7 \mathrm{ff}$. zeigt dann den Mangel an Güte, statt deren in Israel Schauderhaftes verübt wird, an Beispielen weiter auf. 7, 2 endlich kehrt der schon 6, 4 wieder leise angedeutete Gedanke, dafs ihre Handlungen ihnen nicht geצתה : מת statten sich zurückzuwenden, noch einmal wieder סבבום מעלליהם.

Die Analyse der Stelle zeigt, dafs auch hier sich die Bedeutung "Güte", „Wohlthun" für הסר vollkommen bewährt. Als höchste der sittlichen Tugenden, welche die übrigen bedingt, vertritt dieselbe hier die sonst noch neben ihr genannten. Die Verbindung mit רעת אלהים v. 6 ist nach dem zu 4, 1 Bemerkten nicht gegen, sondern für unsere Deutung von ' $\pi$ (gegen Simson zu 6, 6). Ebenso umschreibt schon Raschi v. טובתכם וצרקתכם 4 ' 4 mit, und

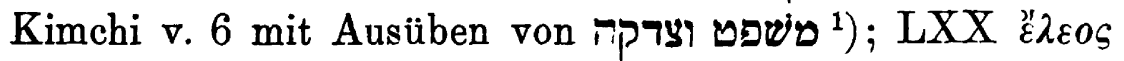
wie 4, 1. 12, 7. Mich. 6, 8, vgl. Mt. 9, 13. 12, 7.

Wesentlich anders steht es aber mit Jer. 2, 2. Zwar

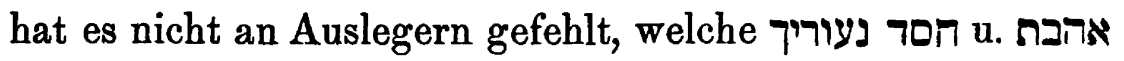
כלוילתיך als die Huld, die Liebe, welche Gott dem Volke in seiner Jugend, während seines Brautstandes erwiesen, gedeutet haben, und noch neuerdings hat Graf im Comm. S. $20 \mathrm{ff}$. diese Auffassung in eingehender Weise begründet. Doch ist sie unhaltbar. Am gründlichsten hat Keil die-. selbe widerlegt; auch Hitzig, Scholz und von Orelli sprechen sich dagegen aus. Die Hauptgründe Grafs gegen die Auffassung von אהבה חסר als Liebe des Volkes zu Gott sind 1) dafs dieselbe in keinem Zusammenhang mit dem Folgenden stehe, wo nur die Rede sei „ ${ }^{\text {von }}$ dem Vergessen der göttlichen Wohlthaten von Seiten des Volks, von seiner Undankbarkeit und Abtrünnigkeit und von der Strafe, die es deshalb zu gewärtigen hat, keineswegs aber von Huld-

1) s. bei Wünsche S. 250. 255 . 
erweisungen Jahwe's wegen seiner früheren Gottergebenheit" (vgl. dagegen v. 3); 2) dafs damit Jeremia sowohl seiner eigenen Anschauung über den Wüstenzug, Israels Jugendzeit, als auch der seiner Zeitgenossen vollständig widerspreche (.kgl. hiergegen die Ausführungen Keils z. St.). Entscheidend wider Graf's Erklärung ist das לכחך אחרי במרבר Diese in synonymem Parallelismus mit den beiden ersten Versgliedern stehenden Worte können nur die. Bethätigung der erwähnten Liebe anzeigen, und ח mufs folglich hier Liebe des Volkes zu Gott bezeichnen. Es ist zu übersetzen : „ich habe dir gedacht der Huld deiner Jugend, der Liebe deines Brautstandes, deiner Nachfolge hinter mir her in die Wüste" u. s. w. Ist etwa damit unsere bisherige Beweisführung durchbrochen? Ist der für höchst unwahrscheinlich erklärte Gebrauch von 70ח im Sinne von Liebe zu Gott doch vorhanden? Nur scheinbar! Eine höchst lehrreiche Parallele zu unserer Stelle bietet Ruth 3, 10 : „Und (Boas) sprach : Gesegnet seist du von Jahwe, meine Tochter, du hast deine Huld (חסרך) besser bewiesen zuletzt als zuerst, dafs du nicht den Jünglingen nachgingst, sei es armen sei es reichen". Hier kann von ' $n$, welche die arme, geduldete Aehrenleserin dem reichen Grundbesitzer gegenüber beweist, die Rede sein, insofern Ruth die Werbung des Boas annimmt und ihn allen übrigen vorzieht. In dieser Hinsicht steht die umworbene Braut über dem sie umwerbenden Manne; das in ' $n$ notwendige Moment der Herablassung ist also vorhanden. Genau wie hier steht es mit Jer. 2, 2, wo das כלולתיך das Bild der Ehe Jahwe's mit Israel andeutet. Jahwe ist der um Israel werbende Mann; dafs Israel gerade seine Werbung annimmt, ihn allen anderen vorzieht und ihm in die Wüste zum Bunde folgt, ist seine חסר Jahwe gegenüber. ' $\pi$ ist darum hier nicht einfach durch „Liebe* oder „Minne ${ }^{\star}$ wiederzugeben, sondern durch „Huld“. Und wohl zu beachten ist, dals der Gebrauch dieses Wortes 
Gott gegenüber hier nur ermöglicht wird durch das ganz bestimmte Bild des Brautstandes zwischen Jahwe und Israel. Nichts wäre unrichtiger, als aus dieser Stelle allgemeinhin die Möglichkeit des Gebrauches von ' $\pi$ vom Menschen Gott gegenüber erschliefsen zu wollen. Ein solch allgemeiner Gebrauch ist nach alledem im A. T. nicht nachzuweisen ${ }^{1}$ ).

Wenden wir uns nun zu den Stellen, die von „Jahwe lieben" (רחם , אהכ) reden, so tritt uns sofort die Thatsache entgegen, dafs dieser Ausdruck nur in 3 vordeuteronomischen Stücken erscheint : im Dekalog Ex. 20, 6, in dem Psalm 18 v. 2 und im Lied der Debora Ri. 5, 31.

Was die Dekalogstelle betrifft, so hat Wellhausen ${ }^{2}$ ) den ganzen $\nabla .6$ unter die Zusätze gerechnet, die infolge einer Rückströmung aus Dt. c. 5 in den Exodustext gelangt seien. Er weist dabei hin auf אהבי, und dies mit Recht; denn im ganzen Hexateuch kennen nur das Dt. und einige deuteronomistische Stellen des Josua den Ausdruck 'אהב ' Dמר מצות ' Dazu kommt ferner das ', durchaus deuteronomische Wendung (vgl. 5, 10. 26. 6, 17. 7, 9. 8, 2. 6. 11. 13, 5 und passim im Dt.). Die älteren Quellen des Hexateuch kennen ' מצות Is terminus technicus für Gebote oder Gesetze Gottes überhaupt nicht, noch weniger den Ausdruck ' משר משר. Das sog. Bundesbuch sagt dafür חקים Ex. 24, 3. 21, 1. In E findet sich דברים ומשפטים ותורות Ex. 18, 16. $20^{3}$ ) und 15, 25; .im Segen Mose's endlich טשפטים ותורה und als Pflicht Levi's

1) Hiernach kann auch חיד nicht soviel sein wie "Gott liebend“. Es bedeutet fromm nach dem Hauptmerkmal des gottgefalligen Wandels, nämlich der Güte.

2) Skizzen und Vorarbeiten II, 89.

3) Ebenso Am. 2, 4 חורה וחקים. Die Stelle wird aber bezweifelt von Duhm, Theologie der Propheten S. 119, Wellhausen, Prolegomena S. 59; so allgemein zu reden ist die Art des Amos sonst nicht, er nennt die Vergehen selbst; die Sprache ist deuteronomistisch. 
שמר אמרת י' ונצר ברית. Nach dem Sprachgebrauch der letz-

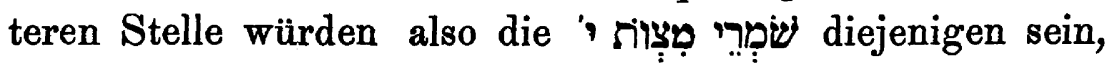
welche die Gebote Jahwes behüten und überliefern, die Priester. Die Stellen, an denen im Zusammenhang von JE ' עצות vorkommt, sind Zusätze oder überarbeitet. So ist Gen. 26, 5 deuteronomistisch (Kuenen ${ }^{1}$ ), Wellh. Skizzen und Vorarbeiten II, S. 23); ebenso Ex. 15, 26 (Kuenen S. 146, Wellh. S. 79). Zu Ex. c. 16 (vgl. v. 28) bemerkt Kuenen (S. 317) : „Es steht fest, dafs dieses Capitel nicht aus $\mathrm{JE}$ herrührt, auch nicht teilweise, vielmehr aus $\mathrm{P}^{2}$, wenn auch nicht in seiner gegenwärtigen, sondern in einer kürzeren Fassung ${ }^{“}$ (vgl. Wellh. S. 79). Ex. 24, 12 ist wohl ein späterer Zusatz zu לחות התורה והמצוה , לאביה, den $\mathrm{R}$ machte, um c. $25 \mathrm{ff}$. unterzubringen (vgl. Dillmann z. St.); jedenfalls ist der Vers nicht mehr in seiner ursprünglichen Gestalt (Kuenen S. 146 f. 318), also nicht zu verwerten. Da nun nachweislich der Exodustext des Dekalogs vielfach nach Dt. c. 5 erweitert worden ist (vgl. Wellh. S. 89, Kuenen S. 160, Dillm., Comment. zu Exodus und Levit. S. $200 \mathrm{f}$.), so scheint mir der sprachliche Beweis für den Ursprung der zweiten Hälfte von Ex. 20,6 aus dem Dt. zwingend zu sein; dann aber dürfte auch die erste Hälfte des Verses kaum zu halten sein. Dillmann führt dagegen an, dals Dt. 7, 9 „diese Stelle schon commentiert ${ }^{\alpha}$. Doch ist 7,9b weiter nichts als eine wortreichere Ausfübrung von 5, 10, welche gegen die Abstammung beider Stellen von ein und demselben Verfasser gar nichts besagen kann, zumal 5, 10 seinerseits wiederum eine Erweiterung von Ex. 34, 7 a ist. Eher könnte man 7, 10 einen Commentar nennen zu 5, 9b, der mit seinem zweimaligen אל-פניו und Kindeskindern überhaupt nicht erwähnt, letztere Stelle vor der Mifsdeutung schützen will, als ob die Kinder un-

1) Einleitung in das A. T. übers. von Weber, 1, 247. 
schuldiger Weise für die Sünden der Väter büfsen mürsten (vgl. Dt. 24, 16. 2 Kön. 14, 6. Jer. 31, 29 f. Ez. c. 18). Dieser Commentar nebst den angeführten Parallelen legt die Vermutung nahe, dafs auch das לשנאי Dt. 5, 9. Ex. 20, 5 „bezüglich der mich Hassenden" vom Dt. hinzugefügt worden ist, um damit auszudrücken, dafs die Kínder nur dann Gottes Heimsuchung treffen werde, wenn sie wie die Väter ihn hassen, nicht aber, wenn sie sich bekehren (vgl. Ez. 18, 14 ff.). Ex. 34, 7 (vgl. Num. 14, 18) hat diesen Zusatz noch nicht. Das Dt. will hierdurch den vorgefundenen Text, mit dessen Fassung es, wie 7, 10 zeigt, nicht recht übereinstimmt, in Einklang setzen mit seinen eigenen Anschauungen. Im allgemeinen verstärken sich die Bedenken gegen die Ursprünglichkeit von Ex. 20, 6 noch durch die Erwägung, dafs die Entfaltung des göttlichen Wesens nach der einen Seite hin als gnädig und barmherzig, nach der anderen aber als strafend und heimsuchend, wohl Ex. 34, 6 f. am Platze ist, nicht aber im Dekalog als Ausführung von Jahwes strafender הקנית.

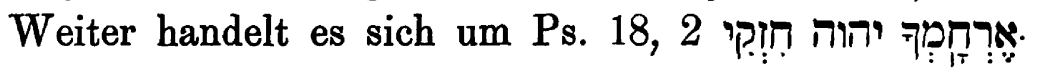
Dieser Vers fehlt 2 Sam. 22, und es fragt sich, ob mit רחם .ארחמך Recht. Zunächst fällt auf das unhebräische heilst im Hebräischen sich erbarmen und wird nur im Piel gebraucht; dagegen ist es im Aramäischen in der Bedeutung

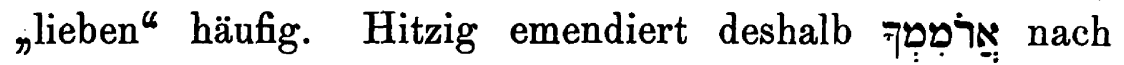
Ps. 30, 2. 145, 1. Jes. 25, 1. Ex. 15, 2, doch ohne Anhalt in den Uebersetzungen. Die ungleich wahrscheinlichere Annahme, die auch durch 2 Sam. 22 gestützt wird, ist, dafs sich der Vers durch seinen Aramaismus als späteren Zusatz zu erkennen giebt, welcher „den scheinbar fragmentarischen Ausrufen Halt und passende Einleitung geben sollte $^{(1)}$ ). Dies wird noch gesichert durch die Beobachtung,

1) Klostermann im Comment. zu den BB. Sam. und der Kön. zu 2 Sam. 22, 2. 
dals die 2 Sam. 22 vollkommen regelmäfsig gebaute, tetrastichische Eingangsstrophe in Ps. 18 durch das Hinzufügen dieses Verses und das dadurch bedingte Auslassen des Strophenschlusses (2 Sam. 22, 3c von ומנוסי an) verletzt worden ist, wie bei einer Nebeneinanderstellung beider Texte sofort in die Augen springt ${ }^{1}$ ) :

2 Sam. 22.

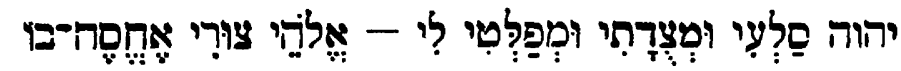

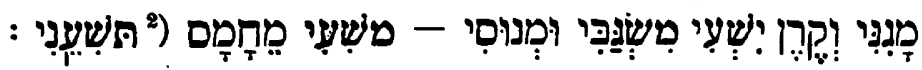

Ps. 18.

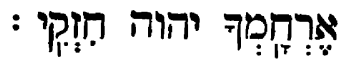

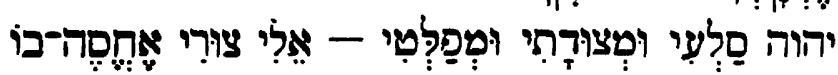

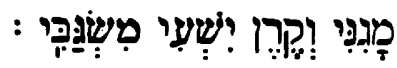

Das über diesen Vers gewonnene Urteil bleibt bestehen, welche Anschauung man sonst auch über das Verhältnis der beiden Textrecensionen des Liedes hat. Auch die streitige Frage nach der Abfassungszeit des 1. Teiles von Ps. 18 ist nach dem Gesagten für uns bedeutungslos.

Hat sich uns aus dem Bisherigen mit Wahrscheinlichkeit die Thatsache ergeben, dafs die älteren Schriften des A. T. eine Liebe zu Jahwe weder als kennen, so stofsen wir schliefslich auf die aufserordentlich befremdliche -Wahrnehmung, dals gerade das vielleicht älteste Denkmal der hebr. Literatur, das Lied der Debora, eine solche kennt $\mathrm{Ri}$. 5, 31. Ich mufs gestehen, dals ich von Anfang an diesem so vereinsamt dastehenden Vers gegenüber ein gewisses Mifstrauen nicht überwinden konnte und dasselbe auch nicht mit der Auskunft Hitzig's zu beruhigen vermochte, dafs hier „ein Weib den Jahwe lieben

1) Vgl. Sommer, Biblische Abhandlungen, Bonn 1846, S. 152.

2) Vielleicht nach $\nabla .49$ zu emendieren מאיצ (Klosterm. a. a. O.). 


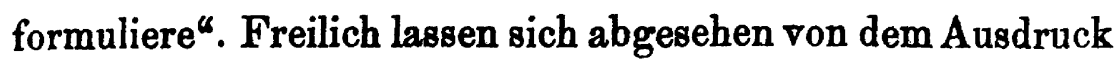
'אהבי schwerlich andere als Bedenken des Geschmacks gegen den Vers geltend machen. Er giebt sich als eine Art Anhang des Liedes. Der eigentliche Schlufs desselben ist von solch überwältigender Kraft und Kühnheit, dafs man ihm im A. T. schwerlich ein anderes Stück wird zur Seite stellen können. Mit unvergleichlicher Wendung führt der Dichter von der Leiche des gemordeten Helden zur Mutter ins Weiberzimmer. Aengstlich lauscht sie durchs Fenster : warum zaudert sein Wagen zurückzukommen? Die Klugen unter ihren Frauen und sie selber antwortet : werden sie nicht Beute gefunden haben und verteilen? Welch schneidende Antithese und welch ungeheurer Spott darin! Hier hat das Lied seinen Höhepunkt erreicht; was noch folgt, mufs abfallen : „Also werden untergehen all deine Feinde, Jahwe! Aber die ihn lieben, sind wie der Aufgang der Sonne in ihrer Kraft." Was soll diese farblose Reflexion, die gleichsam das Facit zieht, eine Moral der Geschichte nachbringen will? Ist der Dichter geschmacklos genug gewesen, sich selbst die Wirkung so zu verderben? Gerade die neueste Arbeit über das DeborahLied 1) zeigt, dafs dasselbe das Erzeugnis eines kunstgeübten Dichters ist. Oder hat sich nicht vielmehr ein Späterer von dem Siegesjubel des Liedes zu eigener Production begeistert gefühlt? Inhaltlich klingt der Vers an zahlreiche Stellen späterer Psalmen an, die in gleicher Weise über die Vernichtung (אבר) der Feinde Jahwe's und das Heil seiner Anhänger triumphieren vgl. z. B. Ps. 37, 20. 68, 3 f. 73, 27. 92, 10 (כי דנה איבך יהוה יאבד). Ich halte den Dichter für einen, der zu dichten verstand, und darum v. 31 für unecht ${ }^{2}$ ). Doch mag man nun zustimmen

1) Aug. Müller in den Königsberger histor.-philol. Studien I, S. 1 bis 21. Königsb. 1887.

2) Der Nachweis Müller's, dafs in der ursprünglichen Form des Liedes, die von v. 16 an noch ziemlich erhalten ist, Distichen mit 
oder nicht : ist der Vers ursprünglich, so stehen jedenfalls hier in ganz äufserlicher Weise die Feinde Jahwe's und damit Israels den Freunden Jahwe's d. h. seinem ganzen Volk gegenüber. Ist der Vers jung, so ist immerhin möglich, dafs der. Verfasser darin nach Art der Psalmen mit den ' אהבי ר die treuen Jahwe-Diener und mit den Feinden die רששים, die gottlosen Gegner des wahren Israels und der wahren Religion, im Sinne hatte.

Jedenfalls ist es das Deuteronomium, welches zuerst auf die Liebe zu Jahwe Nachdruck legt und zuerst das Gebot aufstellt : du sollst Jahwe, deinen Gott, von ganzem Herzen lieben. Dafs dasselbe den Begriff einer Liebe zu Jahwe überhaupt erst in die alttestamentliche Literatur eingeführt hat, ist allerdings nicht sicher nachzuweisen, gilt mir aber nach Vorstehendem für ziemlich wahrscheinlich.

Schon die Stellung, welche das Dt. dem Gebote der Liebe zu Jahwe zuweist, deutet auf die grofse Bedeutung hin, die es ihm beilegt. Nach der Recapitulation der Bundesschliefsung am Horeb steht es 6,5 mit Nachdruck an der Spitze der allgemeinen Ermahnungsreden des Moses (c. 6-11) und diese münden schliefslich wieder in dasselbe ein $(11,1.13 .22)$. Auch die vorliegende Redaction des Dt. wird der Bedeutung dieses Gebotes gerecht, indem sie das Ende der Gesetzesreden eine Ermahnung bilden läfst, die noch einmal kräftig darauf hinweist $(30,6$. 16. 20), so dafs die Reden des Moses in ihrer jetzigen Gestalt davon gleichsam eingerahmt sind. Eine Untersuchung über die Bedeutung der Liebe zu Jahwe im Dt. wird uns zugleich die Wichtigkeit, die gerade dies Gebot für das Dt. hat, erklären.

Tetrastichen wechselten, bringt nichts für und nichts gegen die Echtheit des Verses. Das Lied konnte ebenso gut mit einem viergliedrigen Vers schliefsen wie mit einem zweigliedrigen. Auch sonst wird der V. durch keinも formellen Gründe erfordert.

Zeitschrift f. d. alttest. Wiss. Jahrgang 9. 1889. 
Ich beginne mit der, wie oben nachgewiesen, wahrscheinlich vom Dt. stammenden Stelle des Dekalogs 5, 10. קנט 9 steht hier sicher nicht im Sinne unseres „Hassen", weil dies den hier absurden Gedanken einer dämonischen Gottesfeindschaft ergäbe, sondern es wird, wie auch sonst häufig und vor allem im ehelichen Verhältnis, zu versteben sein als : gleichgültig sein (gegen den Gatten); jemanden vernachlässigen, nicht lieben, dagegen einen anderen (vgl. Gen. 29, 31. Dt. 21, 15. Ri. 14, 16. Mal. 1, 3) ${ }^{1}$ ). Es sind die 'שנהי hier diejenigen, die gleichgültig gegen Jahwe sind, ihn vergessen (שכח) und darum andere Götter lieben und ihnen dienen : die Götzendiener. Dies bestätigt die Stellung hinter den beiden ersten Geboten. Im Gegensatz dazu sind dann die 'אהבי ' diejenigen, die treu zu Jahwe halten und allem götzen- und bilderdienerischen Treiben fern bleiben. Das durch die Liebe zu Jahwe bezeichnete Verhalten wäre demnach hier rein religiös : treue Anhänglichkeit an Jahwe, den Gott Israels, wie sie sich darstellt in reinem Jahwe-Cultus. So bezeichnet Jeremia an zwei Stellen auch den Dienst fremder Götter als Liebe zu ihnen. Jer. 8, 2 : (v. 1 : „Zu selbiger Zeit wird man die Gebeine der Könige von Juda ... und die Gebeine der Bewohner

1) Bemerkenswert ist übrigens, dafs ein ' $N$ Uש, dieser eigentliche Gegensatz des' 'אר Dekalogs nur noch an zwei Stellen von Gliedern des Volkes ausgesagt wird, und zwar in Bezug auf Götzendiener. 2 Chron. 19, 2 wird dem König Josaphat vorgeworfen, dafs or die ' ' Ahab - liebe; letzterer aber ist im Sinne der Chronik natürlich wegen seines götzendienerischen Cultus ein ' שנגֵא wahrscheinlich unter den ' משנאי (vebenfalls die Götzendiener zu verstehen sein (vgl. die Conjecturen zu dem schwierigen, textlich sicher verderbten v. 20 bei Olshausen im Comment. z. St. und bei Graetz in dessen „kritischem Comment. zu den Psalmen“ II, 672). Häufiger dagegen werden die äufseren Feinde des heiligen Volkes Jahwes als

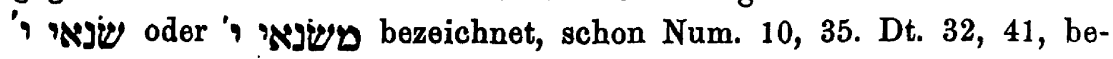
sonders in den Psalmen Ps. 21, 9. 68, 2. 81, 16. 83, 3. 
Jerusalems ...) v. 2 ausbreiten vor der Sonne und dem Mond und allem Heere des Himmels, welche sie geliebt und denen sie gedient haben und denen sie nachgefolgt sind und die sie gesucht und die sie angebetet haben"; und Jer. 2, 25.: ,ich liebe Fremde (ורים) und ihnen folge ich nach" (ורים ist hier nach dem Zusammenhang = fremde Götter vgl. Dt. 32, 16. Jes. 43, 12. Jer. 3, 13 und vielleicht Jer. 5, 19 vgl. Dt. 4, 28). Da Jeremia mit dem Ausdruck lieben hier kaum eine innerliche Hinneigung des Herzens zu den Götzen bezeichnen will, so könnte man vermuten, dafs auch das Dt. das ' אהב י nur in übertragener Bedeutung gebrauche und diejenigen אהבי ' nenne, die Jahwe treu anhängen $d$. $h$. ihn im Sinne des Dt. allein und cultisch recht verehren; und dafs daher auch das Gebot, Jahwe zu lieben 6,5 , keinen anderen Inbalt habe, als die alleinige und die rechte cultische Verehrung Jahwe's zu befehlen. Vielleicht, dafs zur Zeit des Dt. die treuen Anhänger der Cultusreform sich als 'אהבי ורי ורי ihren Gegnern, als den אהבי זרים, gegenüberstellten. Doch ist wohl Jer. 8, אהב als Spott zu verstehen, und 2, 25 erklärt es sich aus dem Bilde der Buhlerei des Volkes mit den Baalen. Gegen die ausgesprochene Vermutung ist entschieden der Zusatz 6, 5. 13, 3. 30,6. Diese echt deuteronomische Wendung (Dt. 4, 29. 6, 5. 10, 12. 11, 13: 13, 3. 26,16 . 30, 2. 6. 10. Jos. 22,5 . 23, 14. 1 Sam. 7, 3. 12, 20. 24. 1 Kön. 2, 4. 8, 23. 48. 14, 8. 2 Kön. 10, 31 vgl. Jer. 24, 7. 32, 41), die sich an allen diesen Stellen nur bei Ausdrücken des Verhaltens

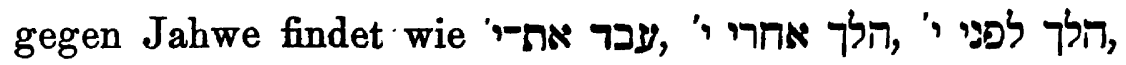
' שוב אל ט u. a., besagt im Effect freilich nichts anderes als das einige Male dabeistehende באמת (vgl. 1 Sam. 12, 24. 1 Kön. 2, 4. Jer. 32, 41), will aber doch hervorheben, dals die ganze Gesinnung (ל)), der ganze Wille (שטכ) und die ganze Kraft (מאר) des Handelnden bei der Sache sein soll. Ferner erscheint Dt. 30, 6 die Liebe zu Jahwe als eine 
Folge der Herzensbeschneidung (vgl. 10, 16) : statt der äufseren Beschneidung, die auch nur eine äufsere Angehörigkeit zu Jahwe begründet, will Gott an Israel eine Herzensbeschneidung vornehmen, die eine innerliche Angehörigkeit, eben die Liebe zu ihm, zur Folge haben wird. Vor allem aber ist zu beachten die Art und Weise, in welcher das Dt. die Liebe zu Jahwe motiviert: Jahwe selbst ist von herzlicher Liebe zu Israel ergriffen. Der Herr des Himmels und der Erde, der grofse, mächtige und furchtbare Gott, hat sich doch nur zu den Vätern Israels geneigt, sie zu lieben $(10,14 \mathrm{ff}$.$) ; er hat sich das Volk$ erwählt, nicht weil es mehr war als andere Völker - im Gegenteil, es ist gering unter ihnen -, auch nicht weil es sich dessen besonders würdig gezeigt hat, sondern aus reiner, unverdienter Liebe und Treue gegen den den Vätern geleisteten Eid (7, 7 ff. vgl. 4, 37. 9, 4 ff.); durch gewaltige Wunder und Zeichen hat er es aus Ägypten erlöst $(6,21 \mathrm{ff} ., 11,3 \mathrm{ff}$.); hat es in der Wüste wie einen Sohn erzogen (8, 1 ff. v. 5. 11, 5 f.); aus kleiner Zahl zu einer Menge gemacht wie die Sterne am Himmel $(10,22)$. Mit all diesen Erinnerungen will das Dt. dankbare Gegentiebe erwecken, wirkliche Zuneigung der Gesinnung. Es sucht durch dieselben den in erhabener Majestät thronenden Gott der Welt dem Volke nahe zu bringen und sympathisch zu machen und den dem Gottesbegriff des Israeliten eigentlich fernliegenden Gedanken einer Liebe zu Jahwe zu vermitteln, indem es zeigt, wie derselbe sich gegen Israel nicht als der erhabene furchtbare Gott, den aller Himmel Himmel nicht fassen können (10, 12 ff. 1 Kön. 8, $27 \mathrm{ff}$ ), sondern als ein liebender Vater offenbart hat $(8,1 \mathrm{ff}$. v. 5 . $.11,5$ f.), der allerdings aber in seiner Eifersucht (4, 24. 5, 9. 6, 15. 29, 19) volle und ungeteilte Erwiderung der Liebe, die er dem Volke erwiesen hat, fordert. Die Liebe zu Jahwe im Dt. läfst sich so vorläufig dahin bestimmen, dafs sie in herzlicher Zuneigung zu Jahwe, als dem Gott 
Israels besteht, und als solche den Beweggrund bilden soll zu treuestem cultischen Dienst unter Fernhaltung von allem götzendienerischen Wesen, wozu im Sinne des Dt.'s neben dem wirklichen Götzendienst auch der Höhen- und Bilderdienst gehört:" Ob diese vorläufige Bestimmung stichhaltig ist, wird sich an den übrigen in Betracht kommenden Stellen zu erproben haben.

Charakteristischer Weise schliefst sich das Gebot der Liebe zu Jahwe an eine Wiederaufnahme des 1. Gebotes des Dekalogs an : „Jahwe unser Gott ist ein einiger Jahwe, Dt. 6, 4 ${ }^{\text {1 }}$ ). Diesem einen Jahwe, seinem Gotte, soll Israel mit ungeteilter Liebe von ganzem Herzen, ganzer Seèle und ganzer Kraft zugethan sein v. 5, so dafs in dieser Forderung eine Verehrung noch anderer Götter neben Jahwe, wie sie die Zeit beliebte (vgl. Zeph. 1, 5), ausgeschlossen ist. Als Gegensatz zu einer derartigen Gesinnung enthält v. 12 das gleichgültige, undankbare Vergessen Jahwe's, des Gottes, der Israel aus Agypten, dem Haus der Knechtschaft, geführt hat' (' 'שכח vgl. 6, 12. 8, 11. 14, 19. 9, 7. 1 Sam. 12, 9 u. ö.), und v. 14 den aus diesem Vergessen hervorgehenden Götzendienst. Einem solchen gleichgültigen Vergessen, einer solchen Untreue gegenüber würde Jahwe's Eifersucht entbrennen, um das Volk zu vernichten v. 15. Es zeigt sich, dafs auch hier die Liebe zu Jahwe eintritt in den Gegensatz zwischen Jahwe-Dienst und Götzendienst; sie soll bewirken, dafs Israel Jahwe fürchtet und nicht fremde Götter, ihm dient und nicht fremden Göttern, zu seinem Namen sich bekennt und nicht zu dem fremder Götter v. 13. Zu beachten ist

1) So mit F. W. Schulz, Knobel, Keil, Dillmann, Baudissin in den Studien zur semit. Religionsgesch. I, 167. Der 1. Teil dieses gewichtigen Verses ${ }_{n}$ Jahwe unser Gott ${ }^{*}$ ist die Losung des Dt.'s gegen den Götzendienst überhaupt. Der 2. Teil, ein einiger Jahwe" bekämpft die Spaltung des Jahwe-Dienstes in verschiedene Ortskulte (vgl. 2 Sam. 15, 7), wie sie der Höhen- und Bilderdienst begünstigte. 
noch, dafs das Gebot der Liebe zu Jahwe an das Volk als Ganzes gerichtet ist. Wenn man die häufige Erwähnung der Eifersucht Jahwe's im Falle der mangelnden Liebe hinzunimmt, so konnte man auf den Gedanken kommen, dals das Dt. seine Forderung der Liebe ableite aus dem Bilde der Ehe Jahwe's mit Israel. Doch finden wir dieses Bild im Dt. niemals gebraucht; es ist dies fast auffällig bei der Innigkeit, mit welchem dasselbe das Verhältnis zwischen Jahwe und Israel ausmalt. Ferner scheidet der Dekalog zwischen solchen, die Jahwe lieben und die ihn hassen, im Volke selbst 5, 10. Dafs sich übrigens das Dt. die gebotene Liebe durch die Liebe des einzelnen zu Jahwe vermittelt denkt, ist selbstverständlich und geht zum Ueberflufs noch aus den Uebungen hervor, die v. $7 \mathrm{ff}$. den einzelnen zur Einschärfung dieses Gebotes anraten.

Ganz ebenso wie 6, 5 ff. liegt das Verhältnils 11, 13 ff. : der Liebe zu Jahwe (innere Herzensrichtung) und seinem Dienst (äufsere Darstellung derselben im Cultus) v. 13, tritt gegenüber die Verführung des Herzens und der Dienst fremder Götter v. 16. Darauf v. 17 wiederum das Entbrennen des eifersüchtigen Zornes Jahwe's. Gleicher Art ist ferner 13, 2 ff. : wenn ein Prophet oder einer, der Träume hat, auftritt und euch unter Zeichen und Wundern, die eintreffen, auffordert : lalst uns fremden Göttern nachwandeln; so sollst du nicht auf ihn hören; denn Gott versucht euch, damit er erkenne, ob ihr ihn von ganzem Herzen liebt. Der Liebe zu Jahwe und seinem Dienst steht wiederum entgegen das Verführtwerden zum Dienst fremder Götter. Der höchsten Macht der Versuchung gegenüber, den Wundern im Namen fremder Götter, welche die Behauptung, dals es neben Jahwe keinen Gott giebt $(4,35$. 39), zu nichte zu machen, ja dadurch, dafs dergleichen als Anreizung zum Abfall im Volke Jahwe's geschehen kann, die Ueberlegenheit der fremden Götter zu beweisen 
scheinen, läfst der Verfasser sich nicht die Furcht vor Jahwe, nicht den Gehorsam gegen seine Gebote - denn alles dies könnte der Erkenntnis der Ueberlegenheit der fremden Götter nicht Stand halten -, sondern die Liebe zu Jahwe bewähren. Nur das Band einer herzlichen Liebe, die sich in Dankbarkeit der Erlösung durch Jahwe erinnert (v. 5), erscheint ihm stark genug, auch gegen die ärgste Verführung zu schützen und die Treue gegen Gott unter allen Umständen zu bewahren. Der gleiche Gegensatz findet sich schliefslich noch 30,16 u. 17. Jos. 23,11 u. $12 \mathrm{ff}$. Besonders lehrreich ist die deuteronomistische Stelle $1 \mathrm{Kön}$. 3, 3 : „Salomo liebte Jahwe, so dafs er in den Satzungen seines Vaters David wandelte; nur auf den Höhen opferte und räucherte er noch" (nach v. 26 kein grofses Vergehen für jene Zeit). Die Ausnahme, welche der Verfasser angiebt, zeigt, was er unter dem Wandeln in den Satzungen Davids versteht : treuen cultischen Dienst Jahwe's. Daran also erkennt der Verfasser die Liebe zu Jahwe. Dieser

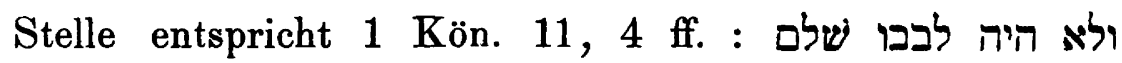
sein Herz war nicht mehr vollkommen mit J. wie das seines Vaters David" d. h. er liebte Jahwe nicht mehr ganz und ungeteilt (vgl. v. 6 ' לא טלא אחרי (v. denn (v. 5 u. 7) er wandelte der Astarte und dem Milcom nach und baute ihnen Altäre. Der Ausdruck' לבב שלם עם tritt bei dem deuteronomistischen Bearbeiter der Königsbb. an Stelle des aufser 1 Kön. 3, 3 nicht gebrauchten ' אהב ' vgl. 1 Kön. 8, 61. 11, 4. 15, 3. 14. 2 Kön. 20, 3 (באטת וכלבב שלם) und das ganz entsprechende בתם-לכב 1 Kön. 9, 4. Ob eines Königs Herz vollkommen bei Jahwe ist oder nicht, entscheidet sich stets nach der Art des Cultus, den er zulälst und selbst treibt. Welchen umfassenden Sinn das Dt. mit diesen Ausdrücken verbindet, zeigt auch Dt. 18, 13 : es soll kein Wahrsager, Zauberer, Zeichendeuter, Totenbeschwörer, kluger Mann u. s. w. bei dir gefunden werden, v. תמים תהיה עם י' 13 
אלהיך, d. h. „du sollst mit Jahwe eine geschlossene, lückenlose Einheit bilden ${ }^{\alpha}$.

Ueberall zeigt sich, dafs sich die Liebe zu Jahwe nicht erprobt an irgend welchen Leistungen sittlicher Art, sondern an der treuen Anhänglichkeit an Jahwe im cultischen Dienst; dafs ferner nicht sittliche Vergehen, Vergehen gegen Recht und Gerechtigkeit $u$. dgl. als Verletzungen der Liebe zu J. erscheinen, sondern stets religiöse, cultische, von grobem Götzendienst an bis zur blofsen Hinneigung zu heidnischem Wesen. So sehen wir die eingangs angedeutete Möglichkeit, dafs im A. T. die Liebe zu J. vermöge des Gegensatzes des Anhangens an anderen Göttern zunächst rein religiösen Inhalt haben könne, beim Deuteronomiker und seinen Schülern als Thatsache vor uns. Die Liebe zu Gott giebt sich hier als ein treues und herzliches Anhänglichkeitsgefühl für Jahwe, den Gott Israels, welches, in der rechten Weise vorhanden, jeden Gedanken an eine Hinneigung zu heidnischem Wesen unmöglich macht. Hiermit aber wird der Unterschied des deuteronomischen Begriffes der Liebe zu Gott von dem neutestamentlichen und christlichen deutlich. Allerdings ist für das christliche Gefühl die Liebe zu Gott, wie im Dt., die volle Hingabe des Herzens an Gott, aber natürlich nicht mehr mit dem Gegensatze des Anhangens an fremde Götter, da die Vorstellung von anderen Göttern neben dem Einen für uns unvollziehbar geworden ist, sondern mit dem der Hingabe an das Widergöttliche, das Sündige, wie sie Johannes als

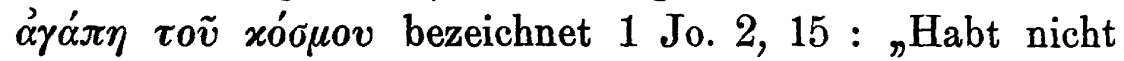
lieb die Welt und was in der Welt ist! So jemand die Welt lieb hat, in dem ist nicht die Liebe zum Vater" (vgl. Jac. 4, 4). Der himmlische Vater wird hier vorgestellt nicht zunächst als der einzige wahre Gott, sondern als das höchste sittliche, überweltliche Gut, und die Liebe zu ihm kann sich daher nur darstellen in der Aneignung seiner überweltlichen, sittlichen Ziele, in der Mitarbeit für das 
Reich Gottes, die sich zusammenfalst in der Liebe zu den Brüdern (1 Jo. 4, 7 ff. 21. 5, 1 ff. vgl. Röm. 13, 8. Col. 3, 14). Eine ähnliche Gedankenverbindung, wenn auch nicht mit der grofsartigen Vereinfachung der ntstm. Sittlichkeit, konnte vielleicht dem Dt., welchem die Verbindung sittlicher Zwecke mit Jahwe, dem Gott Israels, zweifellos feststand (Hosea), sehr nahe liegen; aber es ist zu beachten, dafs es eine solche nie ausdrücklich zieht und niemals ausdrücklich das sittliche Verhalten mit der Liebe zu Jahwe zusammenbringt. Um uns, denen wie gesagt die Vorstellung von anderen Göttern neben dem Einen

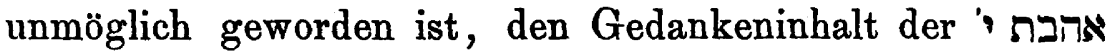
des Dt.'s einigermalsen zu vermitteln, empfiehlt es sich durchaus, im Sinne des Dt.'s nicht von einer Liebe zu Gott, sondern von einer Liebe zu Jahwe zu reden. Denn nicht Gott, das höchste sittliche Gut, ist zunächst Object der Liebe, sondern Jahwe, der Gott Israels. Etwas ähnliches ist es, wenn wir, um das 1. Gebot des Dekaloges für unseren religiösen Vorstellungskreis verwerten zu können, die „anderen Götter" umdeuten in Güter und Schätze der Erde.

Fassen wir die Ergebnisse kurz zusammen. 1) Das Dt. motiviert die Liebe zu Jahwe mit der Liebe und Gnade, welche Jahwe allezeit dem Volk erwiesen hat; diese Liebe soll Israel mit herzlicher Gegenliebe erwidern, mit dem Gefühl ungeteilter, dankbarer Zuneigung zu dem Gott und Retter Israels. Eine solche Liebe schliefst aber notwendig jede Hinneigung zu anderen Göttern, sei's auch nur neben Jahwe, aus. Daher wird sie sich 2) bethätigen in vollständigem Fernhalten von allem heidnischen und götzendienerischen Wesen im Cultus oder, was dasselbe besagt, im Gehorsam gegen die cultischen Satzungen des Deuteronomiums. Jeder Mangel an Liebe, der sich kundgiebt durch Teilnahme am Götzendienst oder den mit dem Götzendienst zusammenhängenden heidnischen Bräuchen, 
reizt Jahwe's Eifersucht und führt die Vernichtung des Volkes herbei.

Dafs das Dt. gerade das Gebot der Liebe zu Jahwe und zwar in dieser Fassung zu seinem Hauptgebot macht, wirft ein helles Licht auf die eigentlichen Absichten und die biblisch-theologische Stellung dieses Buches. Innerlich vermittelt ist dies Gebot durch eine Geschichtsbetrachtung von rein religiösem Standpunkt aus, die nur das jeweilige Verbalten des Volks zu seinem Gott, wie es sich zunächst im Cultus darstellt, durch den Verlauf der Zeiten hindurch mit Interesse verfolgt. Der Geschichte seines Volkes nachgehend erkennt der Deuteronomiker und mit ihm seine Schule, wie dieselbe eine einzige, grolse Kette von Abfall und Götzendienst gewesen ist mit verschwindenden Ausnahmen; wie Israel bei aller Gnade seines Gottes halsstarrig und widerspenstig gewesen ist von jeher; wie es nur von bitterster Not gedrängt zu ihm geschrieen, kaum aber dafs es Hülfe erfahren, schon wieder abgewichen ist (vgl. Dt. c. 1. 9, $7 \mathrm{ff}$. und deuteronomist. Bearbeitung der geschichtl. Bücher). Schuld an alledem ist, dafs Israel nie von ganzem Herzen und von ganzer Seele seinem Gott zugethan war. Dem gegenüber kann sich das $\mathrm{Dt}$. nicht begnügen, seine Satzungen über die wahre Jahwe-Verehrung zu starrem Gehorsam einfach anzubefehlen - die Geschichte zeigt ihm, wie nutzlos dies wäre -, sondern es sucht diesen Gehorsam innerlich zu motivieren durch die Forderung einer ganz neuen Herzensstellung zu Jahwe (vgl. 10, 16. 30, 6), der Liebe zu ihm, welche ein so wankelmütiges Verhalten wie bisher überhaupt unmöglich macht (vgl. oben zu 13,4) und eine ebenso unlösbare Anhänglichkeit des Volkes an seinen Gott begründet, wie sie Gott dem Volke gegenüber vermöge seiner Liebe zu ihm allezeit bewiesen hat. Dafs sich die Forderung einer solchen Liebe nicht eigentlich als Satzung aufstellen läfst, findet darin seinen Ausdruck, dars das Gebot der Liebe 
nicht in der Gesetzessammlung selbst erscheint, sondern nur in der paränetischen Einleitung, und dafs demnach das Dt. in derselben mehr eine freiwillige Liebe des Herzens zu Jahwe durch die Erinnerung an all seine Gnadenerweisungen erwecken will, als darüber ein Gesetz geben.

Der Gedanke, dafs es auf eine Hingebung des Herzens an Gott ankomme, dafs man Jahwe nicht mit dem Munde und den Lippen, sondern mit dem Herzen verehren müsse Jes. 29, 13, ist natürlich älter als das Dt., er liegt der gesammten prophetischen Predigt vor demselben zu Grunde. Aber wohl zu beachten ist, dafs das, was diese Propheten mit der Hingebung des Herzens an Gott - oft durch die ' רעת רusgedrückt - fordern, nämlich Erweisung derselben im sittlichen Wandel, im Ausüben dessen, was man als Gottes Willen und Wesen innerlich erfährt, d. h. im Thun von Recht und Gerechtigkeit und Güte, sich durchaus nicht deckt mit dem Inhalt der ' אהבת י des Dt.'s, dem Motiv einer reinen Jahwe-Verehrung. Wenn die Propheten jeden Cultus, auch den rechtmäfsigen, weit zurücksetzen hinter den Gottesdienst, der im Üben von Recht und Gerechtigkeit besteht (Am. 5, 21 ff. Hos. 6, 6. Jes. 1, 11 ff. Mich. 6, 6 ff.), so fordert das Dt. deswegen die Liebe zu Jahwe, um darin eine sichere Gewähr nicht eines reichen Cultus - denn die Absicht des Dt. ist mehr denselben zu beschränken als zu vermehren - aber eines reinen Cultus zu haben. Es ist in der That eine nicht geringe Kluft, die zwischen dem Dt. und den Propheten des 8. Jahrhunderts in dieser Hinsicht offen steht. Wenn die Propheten allen ibren religiösen Gedanken sofort eine praktisch-sittliche Richtung geben; wenn dieselben charakteristischer Weise einen Ausdruck, der sich auf das Verhältnis zwischen Gott und Volk beschränkt, wie das Dt. sich ihn in dem ' אהב ' geprägt hat, nicht verwerten; wenn bei ihnen das Vorrecht der Liebe und Gnade nur Gott hat, das Volk dagegen 
nur die Pflicht, sich Gottes Willen unterzuordnen ('יראת (יר ${ }^{1}$ ) und sein sittliches Verhalten nach Gottes Wesen zu bilden ('רעח (ר), so überwiegt beim Dt. das Interesse für das religiös-cultische Verhalten des Volkes, das sich im Gebot der Liebe zu Jahwe zusammenfafst, alles andere bei weitem. Auch Hosea, auf dessen Verwandtschaft mit dem Dt. Duhm a. a. O. S. 126 ff. $197 \mathrm{ff}^{2}$ ) mit Recht aufmerksam macht, steht in diesem Betracht doch ganz auf Seite der Propheten seiner Periode (gegen Duhm, der ihm einseitige Ueberschätzung des religiösen Momentes vorwirft S. 127). Allerdings kämpft Hosea mit gleichem Eifer wie das Dt. gegen Höhen- und Bilderdienst, der ihm als heidnisch gilt, weil er den Dienst Jahwe's mit einer sinnlichen Naturreligion vermischt (vgl. 2, 18 f. und Duhm a. a. O. S. 128 ff.); aber während das Dt. dafür nur den rein religiösen Grund hat, dafs jede Berührung des Volkes mit heidnischem Wesen für Jahwe ein Gräuel ist, etwas was er hafst und nicht ertragen kann (vgl. z. B. 7. 25 f. 12, 29 ff. 18, 9 ff.), wird Hosea's Polemik vielmehr dagegen erregt durch die Beobachtung der entsittlichenden.Wirkung dieses Dienstes, welche Israel vergessen lälst; dafs Jahwe mehr von ihm fordert als Rinder und Schafe, als das Häufen von Opfern und Altären (5, 2. 6. 8, 11. 13. 10, 1 ff.), dafs ein wahrer Gottesdienst nicht in unsittlichen Gelagen auf den Höhen besteht (4, $13 \mathrm{ff} .9,15.10,15)$, sondern im Ausüben von Recht und Güte (4, 1. 6, 4. 6. 10, 12. 12, 7). Darum sieht Hosea eine wahre Umkehr zu Jahwe nicht etwa blos in der Abschaffung des als heidnisch erkannten Cultus, sondern in einer Änderung des ganzen sittlichen Wandels von Grund aus $(10,12)$, und seine Forderung der Gotteserkenntnis $(2,22.4,1.6 .5,4.6,3.6 .8,2)$, die bei ihm

1) Auch der Messias des Jesaia natmet" in der Furcht Jahwe's, nicht aber in der Liebe Jes. 11, 3.

2) vgl. dazu die Bemerkungen Nowack's im Comment. zu Hosea S. $\mathrm{XXX}$ f. und an vielen Stellen der Auslegung. 
eine an Wichtigkeit dem deuteronomischen Gebot der Liebe zu Jahwe etwa gleiche Stellung einnimmt, geht nicht so sehr auf eine Erkenntnis und Ausübung des reinen Cultus, als vielmehr auf eine innere Erfahrung des gerechten und gütigen Westens Gottes und auf Bethätigung dieser Erfahrung im Thun von Gerechtigkeit und Güte $(2,21$ f. 4 , 1. 6, 6. 5, 4). So kann der richtig verstandene V. 6, 6 geradezu der centrale Gedanke der prophetischen Predigt des Hosea genannt werden, und in diesem Gedanken stimmt Hosea ganz mit einem Amos, Jesaia, Micha überein.

Man könnte vielleicht diese Beurteilung des Dt.'s mit Hinweis auf die Gesetzessammlung selbst, welche zu ihrem gröfserem Teile aus Rechts- und Sitten-Satzungen besteht, zum kleineren aus cultischen, stark übertrieben finden. Dagegen ist darauf hinzuweisen, dafs diese Rechtsund Sittensatzungen sich einerseits darstellen als Wiederholungen aus dem älteren Bundesbuch Ex. 20-23 und den Bundesworten Ex. c. 34 mit den durch das Gebot der Cultuseinheit und,durch die spätere Zeitlage bedingten Veränderungen und in der breiten Sprache des Deuteronomikers, andererseits als vielleicht erstmalige Codifizierung längst unter Mose's Autorität aufgestellter Forderungen; dafs hingegen das Dt. Neues nur in seinen Cultusgeboten bringe, hier wenigstens in gewisser Hinsicht schöpferisch sei. Und es ist klar, dafs ein Gesetzbuch, welches sich als die Thora des Mose gab, jene unter Mose's Namen überlieferten Rechts- und Sittensatzungen mit aufnehmen mufste, auch wenn sein eigentliches Interesse nicht in dieser Richtung lag. Doch sind dergl. Erwägungen zu allgemein, um irgendwie als bindend erscheinen zu können. Einen zwingenden Beweis dagegen für die Richtigkeit unserer Beurteilung des Dt.'s bringen die paränetischen Einleitungs- und Schlufsreden desselben - mögen sie nun vom Gesetzgeber selbst herrühren oder nicht - und die deuteronomist. Bearbeitung der geschichtl. Bücher. Man 
wird zugeben müssen, dafs die Verf. dieser Stücke, welche ganz aus der Sprache und dem Geiste der deuteron. Gesetzgebung heraus geschrieben sind, besser fühlen mufsten, was in den Gesetzen die Hauptsache, was nur Nebenwerk war, als wir dies jetzt zu beurteilen im Stande sind. Und der Beweis, dafs diese Männer vollständig in einem religiös-cultischen Interesse befangen sind, läfst sich leicht erbringen.

Wenn sie immer und immer wieder hervorheben, dafs das Schicksal des Volkes, sein Leben oder Untergang, ganz davon abhänge, ob es Jahwe treu dienen oder sich mit Götzendienst beflecken wird (vgl. z. B. Dt. 6, 15. 7, 4. 26. 8, 19. 11, 17. 26 ff. $28,20.29,24$ ff. 30,17 ff. Jos. 23 , $12 \mathrm{ff} .24,19$ ff.), wird die Frage, was denn geschehen soll, wenn das Volk sich mit groben sittlichen Vergehen verschulden, nicht Recht und Gerechtigkeit, nicht Nächstenliebe beobachten wird, nirgends auch nur berührt. Ueberhaupt nehmen die paränetischen Reden des Dt.'s auf derlei Dinge an keiner einzigen Stelle Rücksicht ${ }^{1}$ ). Berührt ist ferner schon, wie die Bearbeitung der Königsbb. ihr Urteil über die einzelnen Könige stets einzig und allein nach deren cultischer Stellung bemifst. Nur bei Manasse erwähnt sie auch das viele unschuldige Blut, das er vergofs (2 Kön. 21, 16. 24, 4), was in diesem Falle leicht zu begreifen ist, da dies das Blut der treuen Propheten und Priester Jahwe's war. Unter den Gründen, weswegen das Nordreich unterging, weifs sie nur cultische, kein einziges sittliches Vergehen zu nennen (2 Kön. c. 17). Bei jenen Anhäufungen ferner von Ermahnungen zum Gehorsam gegen Jahwe und seine Gebote (Jahwe zu dienen, in seinen Wegen zu gehen, auf seine Stimme zu hören, seine Satzungen und Rechte zu beobachten), wie sie sich im Dt. und im B.

1) Dt. 10, 19 ist Einschub nach Lev. 19, 34; vgl. Valetou, Studien in der Theol. Tijds. VI, 171 und Dillmann z. St. 
Josua aulserordentlich häufig finden (z. B. vgl. Dt. 10, 12 f. $20.11,1.13,4.17,19.19,9.28,13$ f. 30,16 ), zeigt sich einer näheren Betrachtung ebenfalls, dafs dem Verf. zunächst überall nur der eine Gegensatz des Abfalls zum Götzendienst vorschwebt. An und für sich klar ist

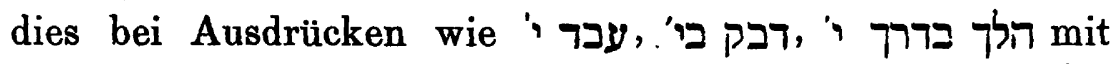

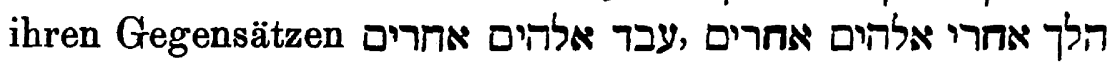
(z. B. Dt. 6, 14. 7, 16. 8, 19. 11, 16. 28 und ö.). Auffällig aber ist, dafs der Verfasser, selbst wenn er Ausdrücke wie nalle Satzungen und Rechte und Gebote Jahwe's beobachten, auf Jahwe's Stimme hören " und ähnl. anwendet, doch nur die Satzungen über die alleinige und rechtmälsige JahweVerehrung im Auge hat. Man vergleiche z. B. 8, 11, wo "den Geboten, Rechten und Satzungen nicht gehorchen" soviel ist wie „Jahwe vergessen", d. i. nach v. 19 ,anderen Göttern nachgehen; 11, 13, wo „auf die Gebote hören ${ }^{\text {" }}$ soviel ist wie "Jahwe lieben und ihm dienen", mit dem Gegensatz v. 16 „von Jahwe abfallen"; 11, 28, wo „den Geboten nicht gehorchen" soviel ist wie „abweichen von Jahwe's Wege und anderen Göttern nachgehn"; 28, 13 f., wo „den Geboten Jahwe's, die Mose heute gebietet, gehorchen und nicht weichen von allen seinen Worten zur Rechten oder Linken" schliefslich nur hinausläuft auf nan- $^{\text {an }}$ deren Göttern nachzugehn und ihnen zu dienen " (vgl. noch v. 15 mit v. 20); Jos. 23, 6 f., wo gegenübersteht „beobachten und thun alles, was geschrieben steht im Gesetzbuch Mose's" und v. 7 „das Dienen und Anbeten fremder Götter". Diese Liste liefse sich leicht vermehren. Das auffallendste Beispiel gleicher Art aus der Bearbeitung der Königsbb. ist 2. Kön. 17, 16, wo die Anklage, dafs Israel „ alle Gebote Jahwe's verlassen", näher dahin ausgeführt wird, „dafs es gegossene Bilder, zwei Kälber und Ascheren machte, das ganze Heer des Himmels anbetete, den Baalen diente, seine Söhne und Töchter durchs Feuer gehen liefs und Wahrsagerei und Zeichendeuterei trieb ${ }^{\star}$. Diese Stellen reden deutlich ge- 
nug. Diesen Schriftstellern verschwindet eben alles hinter der einen Frage : Götzendienst oder Jahwedienst, heidnischer Höhendienst oder gereinigter Cultus. Endlich ist noch zu erinnern, dafs auch die Reform des Josia sich nur auf den Cultus richtet (2 Kön. 22. 23), dafs wir von einem Versuch, auch die übrigen Bestimmungen durchzusetzen, schlechterdings kein Wort lesen. Gewifs gab es auch Kreise, welche das ganze Gesetz des Dt.'s mit Eifer erfalsten. Dies zeigt uns der unter Zedekia's Regierung unternommene Versuch, das Sklavengesetz Dt. 15, $12 \mathrm{ff}$. zur Geltung zu bringen, den man wohl auf Anregen dieser Kreise zurückführen kann (vgl. Jer. 34, 8 ff.). Es charakterisiert Jeremia, den Propheten, dafs er in dem Mifslingen desselben einen Abfall von Jahwe erblickt. Um so auffälliger mufs es erscheinen, dafs die eigentlichen Urheber des Deuteron., denen es wohl ein leichtes gewesen wäre, den unter ihrem Einflufs stehenden Josia zu einem Versuch einer Durchführung auch der socialen und rechtlichen $\mathrm{Ge}$ setze zu vermögen, hierzu gar nichts gethan oder wenigstens nichts erreicht haben (2 Kön. 22. 23).

Dieses Ueberwiegen des religiös-cultischen Interesses im Deuteronomium erklärt und bestätigt zugleich die oben gegebene Auffassung seines Begriffes der Liebe zu Jahwe, die wir, ohne zunächst auf diesen besonderen Standpunkt des Dt.'s Rücksicht zu nehmen, fanden. Reinheit des Cultus, peinlichstes Fernhalten von allem heidnischen Wesen, d. i. Gehorsam gegen die gegebenen Cultusgebote, ist Ziel und Zweck des Dt.'s; dieser wird Israels Gerechtigkeit sein 6, 25, sein Heil und seine Rettung. Das Gebot der Liebe zu Jahwe verhält sich zu diesem eigentlichen Zweck wie das zur Verwirklichung jenes Gehorsams als unentbehrlich erkannte Motiv.

Schliefslich noch einige Worte über die im Anschlufs an Dt. 6, 5 und Mt. 22, $34 \mathrm{ff}$. oft aufgeworfene Frage, ob das Gebot der Liebe zu Gott im Verhältnis zur übrigen 
Thora eine principielle Stellung einnimmt, und die damit eng zusammenhängende, ob das altt. Gebot der Liebe zu Gott, wenn Jesus dasselbe Mt. 22, 37 wieder aufnimmt, mit unter das Urteil von Mt. 5, 17 fällt oder nicht ${ }^{1}$ ). Von einem Princip des Gesetzes oder der Sittlichkeit kann man überhaupt im A. T. nicht reden. Princip könnte man auch die Liebe zu Jahwe nur nennen, wenn die einzelnen Gebote der Thora aus ihr entwickelt würden, wenn sie als Forderungen aufgestellt würden, die im Wesen Gottes selbst begründet wären, und die deshalb mit der Liebe zu Gott notwendig angeeignet würden, wie die Forderungen der christlichen Ethik. Nun ist aber die Thora ja nichts weniger als eine Ethik im christlichen Sinne, vielmehr ein casuistisches Gesetzbuch mit allerlei einzelnen cultisçhen, rechtlichen und sittlichen Geboten ohne organischen $\mathrm{Zu}$ sammenhang; wie denn überhaupt das A. T. eine Ethik in unserem Sinne nicht kennt und nicht zu kennen vermag, da in der altt. Anschauung die Grenzen von Recht, Volkssitte und Sittlichkeit noch in einander fliefsen ${ }^{2}$ ). Die Liebe zu Jahwe könnte also höchstens in Betracht kommen als Motiv des Gehorsams gegen die Gesammtheit der in der Thora fixierten cultischen, rechtlichen und sittlichen Satzungen. Oben ist aber gezeigt, dafs das Dt. dieselbe nur dem cultischen Verhalten gegenüber in eine solche Beziehung bringt, die übrigen Gebote nicht ausdrücklich daraus ableitet.

Andererseits sind wir vollauf berechtigt, im N. T. die Liebe zu Gott das Princip der christlichen Sittlichkeit zu nennen. Es kommt hier vor allem in Betracht 1 Jo. 4, 7 ff. 5,1 ff. „Gott ist die Liebe $(4,8)$ und die christ-

1) vgl. z. B. F. W. Schultz und Keil zu Dt. 6, 5; de Wette zu Mt. 22, 40; Olshausen zu Mt. 22, 38.

2) vergl. die. Bemerknngen von H. Schultz über das Verhältnis des Glaubens zur-altt. Sittlichkeit, Bibl. Theol. des A. T. ${ }^{8}$ S. 309. 
liche Sittlichkeit falst sich zusammen in der Bruderliebe (4, 7 vgl. v. 12. Röm. 13, 8). Jeder aber, der von Liebe zu diesem Gott durchdrungen ist, welcher der Menschheit gegenüber die Liebe ist, muls (nach innerer Notwendigkeit, nicht vermöge blofsen Gehorsams) auch die lieben, welche Gott liebt (vgl. 1 Jo.5, 1. 4, 21). In diesem Sinne ist es sicher auch gemeint, wenn Jesus (Mt. 22, 34 ff. Mc. 12, $28 \mathrm{ff}$. vgl. Luc. 10, $25 \mathrm{ff}$.) als die zwei gröfsten Gebote, an denen das ganze Gesetz und die Propheten hangen, Gottes- und Nächstenliebe (nach Dt. 6, 5. Lev. 19, 18), also ein Doppelgebot nennt. Die höhere Einheit desselben zeigt eben Johannes. Der Unterschied der Bedeutung des Gebotes der Liebe zu Gott im A. T. (nach dem Dt.) und im N. T. lälst sich also dahin zusammenfassen, dals dasselbe im Dt. als ein rein religiöser Begriff das Grundmotiv bildet zum Gehorsam gegen die cultischen Satzungen der Thora, im N. T. als religiös-sittlicher Begriff die treibende Kraft alles christlich-sittlichen Handelns ist.

Inwieweit sich im A. T. diese ntestm. Auffassung der Liebe zu Gott angebahnt findet, lassen leider die wenigen nachdeuteronomischen Stellen, welche von der Liebe zu Jahwe reden, bei dem äufserst geringen Anhalt, welchen sie für eine nähere Bestimmung dieses Begriffes bieten, nicht genauer beobachten. Es zeigt sich hierin, dals der Gedanke einer Liebe zu Jahwe dem Israeliten doch nicht nahe lag. Er vermochte auch in den späteren Büchern des A. T.'s keine feste Wurzel zu schlagen; in der ganzen Chokmaliteratur, welche die Furcht Jahwe's so oft als das A und $\mathrm{O}$ menschlicher Weisheit preist, wird einer Liebe zu Jahwe nirgends Erwähnung gethan. An und für sich lälst sich wohl vermuten, dafs mit dem Zurücktreten des scharfen Gegensatzes zwischen Jahwe- und Götzendienst im Volke und mit dem Aufhören der bitteren Kämpfe, die sich an denselben knüpften, der Begriff der Liebe zu Jahwe seine besondere Richtung auf den reinen Cultus verloren, dals 
man die Bethätigung der Liebe in der treuen Gesetzeserfüllung überhaupt gesehen habe. Es ist dies eine Auffassung, die auch dem Dt., wie gesagt, sehr nahe liegen mufste, wenn es dieselbe auch seines einseitig religiöscultischen Interesses wegen nirgends ausdrücklich hervorhebt, und welche daher die späteren Leser, die eben jenes Interesse nicht mehr in dem Malse hatten, sicherlich aus demselben herausgelesen haben. Wir finden dieselbe vor allem Ps. 119, 132, wo „den Namen Jahwe's lieben“ (d. i. eigentlich soviel wie Jahwe's offenbares Wesen lieben, doch schliefslich nichts anderes als Jahwe lieben vgl. Ps. 69, 37. 5, 12. Jes. 56, 6) einfach als Abwechslung auftritt für : diè Gebote, die Thora lieben v. 47. 48. 97. 113. 119. 127 u. ö. Ferner werden oft'die ', אהבי den Frevlern und Gottlosen gegenübergestellt, so Ps. 5, 12 v. 11. 145, 20. 31, 24, wobei allerdings zu beachten ist, dafs das Hauptmerkmal dieser רשעים in den Psalmen doch immer ihre Gegnerschaft gegen Jahwe ist.

Eine eigentümliche Stellung nimmt Ps. 97, 10 ein. Ps. 97 gehört einer Gruppe von Psalmen (Ps. 95-100) an, die höchst wahrscheinlich unmittelbar nach der Rückkehr aus dem Exil gedichtet sind, und die sämmtlich die Erlösung aus der Gefangenschaft durch Jahwe preisen ${ }^{1}$ ); derselbe dürfte.also zeitlich dem $D$ t. nicht allzufern stehen. Er rühmt im Eingang Jahwe's gewaltige Thaten, die alle Völker gesehen haben ( vor ihm zu Schanden und alle Götter beten ihn an ( $\nabla .7)$; Zion und Juda frohlocken über seine Strafgerichte ( „Denn du, Jahwe, bist erhaben über die ganze Erde, hast dich hoch erhaben über alle Götter gezeigt" (v. 9). An diesen Lobpreis schliefst dann der Dichter die Mahnung : „die ihr Jahwe liebet, hasset das Böse!“ (v. 10a). Hitzig hat diese Worte auffällig gefunden, da die Liebe zu Jahwe

1) Graetz a. a. O. II, 526 ff. 
den Hafs des Bösen notwendig schon in sich schliefse, und

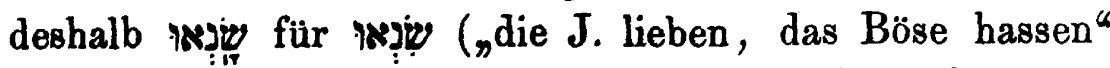
u. s. w.) verbessert ${ }^{1}$ ). Doch scheint mir diese Correctur den an und für sich schon nicht besonders klaren Bau des Verses nur noch verwickelter zu machen. Das Richtigere dürfte sein, wenn Graetz in diesem Verse ,einen leisen Tadel gegen unangemessenes ethisches Verhalten ${ }^{*}$ der ' אהבי erblickt und meint, derselbe setze voraus, , dafs diese 'אהבי ר nicht immer das Böse gemieden haben" (a. a. O. S. 529. 533). Dann aber sind hier die wie im Dt. die treuen Anhänger Jahwe's, diejenigen welche sich treu zu Jahwe's Namen bekennen, die „Freunde Jahwe's" im Gegensatz zu den vorher genannten Götzendienern (v. 7). Dieselben werden aufgefordert, sich auch sittlich gemäfs der Erhabenheit des Gottes, dem sie dienen, zu erweisen d. h. als Als solche wird sie dann Jahwe beschützen : „Behütend die Seelen seiner wird er sie aus der Hand der Frevler retten" (v. $10 \mathrm{~b}$ ). Diese חסירים treten also gemäls des fortschreitenden Gedankengangs nicht einfach als Abwechslung der אהבי ו 'אי auf, sondern bezeichnen diejenigen, welche sich im sittאוchen Handeln, im Ausüben von חסבי ' אסר, als wahre erweisen. v. $10 \mathrm{~b}$ begründet also die Mahnung von v. $10 \mathrm{a}$. Das Wichtige der Stelle ist, dafs der Verfasser hier ausdrücklich von einem wahren ' אה kommenheit fordert.

In Ps. 31, 24 - übrigens der einzigen Aufforderung zur Liebe Jahwe's in den Psalmen - erscheint dieselbe wie im Dt. als Ausdruck des Dankes für seine Güte (vgl. จ. 20 ff.). Abraham ist Jes. 41, 8. 2 Chron. 20, 7 der אה אה אהב schlechthin. hat hier wohl fast den Sinn von unserem ${ }_{\text {Freund }}^{\star}$ (vgl. Jacob. 2, 23). Merkwürdig ist,

2) Riehm in der 2. Aufl. von Hupfeld's Psalmen zollt dieser Emendation Boifall. 
dafs wir in den Psalmen fast nirgends der Liebe zu Jahwe als dem Ausdruck des subjectiven religiösen Gefühles Gott gegenüber begegnen, nur in dem erst später hinzugesetzten Vers Ps. 18, 2 und Ps. 73, $25:$, Wen habe ich im Himmel (neben dir), und auf Erden liebe ich nichts (לא חפצתי) neben dir!" ( Wenn ich nur dich habe, so frage ich nichts nach Himmel und Erde." ) In der mystischen Versenkung in Gott, in seiner Gemeinschaft als dem höchsten Gut, vergifst der Dichter die ganze Welt mit all ihren Schätzen und findet so sein volles Gleichgewicht wieder gegenüber der Wahrnehmung des Glückes der Gottlosen ( Gott nahe zu sein, ersetzt ihm alles Glück der Erde (v. 28). Gewifs ist diese Versenkung in Gott verschieden von dem, was das Dt. mit der Liebe zu 'Jahwe, dem einfachen Gefühl dankbarer Anhänglichkeit an den Bundesgott, bezeichnet. Man kann sagen, dafs die Liebe zu Gott hier intensiv verinnerlicht erscheint, ja dafs schon hier der ntestm. Gegensatz einer Liebe zur Welt angedeutet ist, ohne doch damit die Meinung verbinden zu dürfen; dafs das Gefühl, welches diese erhabenen Worte aussprechen, vollkommen identisch ist mit dem Inhalt, den das $\mathrm{N}$. T. der Liebe zu Gott giebt. Denn die Verachtung alles Irdischen, welche der Psalmist bekennt, gleicht doch mehr der Weltflucht des Mystikers als der Weltüberwindung, welche das N. T. fordert. Im N. T. ist die Liebe zu Gott nie ein weltvergessendes Versenken in Gott und ein Ausruhen in seinem Schofse allein, sondern stets gedacht als innerster Antrieb zur sittlichen Bethätigung in der Welt in Bruderliebe und Berufserfüllung, d. i. zur Weltüberwindung (vgl. Joh. 14, 31. 1 Joh. 4, 21. 5, 2 f.) ${ }^{1}$ ). So lärst uns dieser erbabenste Flug, den die alttestamentliche Dichtung zum Himmel empor nimmt, doch zugleich die

1) Vgl. Ritschl, Rechtfert. u. Versöhn. 3. Aufl. II, S. 99 f.; uuch Duhm a. a. O. S. 247. •. 
Schranken erkennen, an welche die Religion des A. B. gerade in ihrer böchsten und reinsten Entwicklung stofsen mulste. Die Lösung der Rätselfrage : was soll ich in und mit der Welt, wenn doch mein wahres Leben nur in Gott sein kann, der Frage, die Christus durch die Gründung eines Reiches Gottes und durch die Aufforderung, für Gott in demselben zu wirken, beantwortete, gelang ihr noch nicht und konnte ihr noch nicht gelingen.

\section{Alttestamentliche Studien in Amerika.}

Von Prof. G. Moore in Andover.

II. Die neueste Zeit : jetziger Stand der Wissenschaft.

Wie am Anfang dieses Jahrhunderts die Arbeiten Stuarts und seiner Schüler in der Geschichte der alttestamentlichen Studien in Amerika Epoche machten, so ist nun in den letzten Jahren unsere Wissenschaft wieder in ein neues Stadium getreten. Die mittleren Dezennien des Jahrhunderts waren für Amerika eine Uebergangsperiode, die, wie im Leben des Einzelnen der Uebergang von der Jugend zum Mannesalter, manche neue Aufgaben mit sich brachte, aber auch manch neue Gefahr. Die riesigen materiellen Fortschritte, deren wir uns rühmen dürfen, haben die geistige Entwickelung gehemmt. Die socialen und politischen Gegensätze zwischen den Nord- und Südstaaten, die auf die Ausbreitung der Sklaverei in den Bundesterritorien zielende Politik der letzteren, wie die mit religiösem Eifer geleitete Bewegung für die Aufhebung der Sklaverei in den Nordstaaten, führten unvermeidlich zu dem Sezessionskrieg (1860-65). Der Sieg der Union machte der Sklaverei ein Ende und verlieh den befreiten Negern das, ihren früheren Eigenthümern zum Theil ent- 